OPEN ACCESS

Edited by:

Mónica Ivelisse Feliú-Mójer, University of California, San Francisco,

CA, United States

Reviewed by:

Pieter Maeseele,

University of Antwerp, Belgium

Guillermo Douglass-Jaimes,

Pomona College, United States

*Correspondence:

Emily Polk

empolk@stanford.edu

Sibyl Diver

sdiver@stanford.edu

Specialty section

This article was submitted to

Science and Environmental

Communication,

a section of the journal

Frontiers in Communication

Received: 02 August 2019

Accepted: 28 January 2020

Published: 21 February 2020

Citation:

Polk E and Diver S (2020) Situating the Scientist: Creating Inclusive Science Communication Through

Equity Framing and Environmental

Justice. Front. Commun. 5:6.

doi: 10.3389/fcomm.2020.00006

\section{Situating the Scientist: Creating Inclusive Science Communication Through Equity Framing and Environmental Justice}

\author{
Emily Polk ${ }^{1 *}$ and Sibyl Diver ${ }^{2 *}$ \\ ${ }_{1}^{1}$ Program in Writing and Rhetoric, Stanford University, Stanford, CA, United States, ${ }^{2}$ Department of Earth System Science \\ Stanford University, Stanford, CA, United States
}

This article draws on environmental justice (EJ) scholarship to develop a novel concept of equity framing that can be used to achieve more inclusive science communication. We argue that centering equity in our communications framing can provide an essential point of access for marginalized communities to engage with scientific communication, and also an important opportunity for scientific researchers and writers to become more accountable to disadvantaged communities. Viewing science communication through an equity lens asks communicators to not only frame science in ways that are salient to particular audiences, but it also asks communicators to attend to particular discriminatory historical practices that have targeted marginalized communities, and continue to do so through current scientific discourse. EJ strategies for equity framing include asking science communicators to (1) become aware of their own positionality and partial perspectives, (2) name sources of inequity that arise from uneven power relations, and (3) find intersections with initiatives that are rooted in the experiences of disadvantaged communities. To ground our approach to equity framing, we also present our experiences teaching Stanford University's first comprehensive class on environmental justice as a case study. Key outcomes included: adding missing perspectives to scientific knowledge production by inviting representatives from diverse and marginalized communities to teach us; increasing the social relevance of scientific findings by asking our students to center the concerns and insights of marginalized communities in their communication; and encouraging collective action to address equity concerns and achieve a healthier society for all.

Keywords: environmental justice, scientific discourse, positionality, equity framing, EJ pedagogy

\section{INTRODUCTION}

In this article, we map out a process for more inclusive science communication grounded in the practices of environmental justice (EJ), with a specific focus on communication of the environmental sciences. We ground our analysis in the history of the EJ movement as it emerged as a transformative paradigm that has centered the fight for equity in environmentalism through a variety of discursive strategies (Bullard, 1993, 1996, 2000; Taylor, 1997, 2000; Pellow, 2016). 
We argue that science communication, as a field of inquiry and practice, must undergo a similar paradigm shift-namely through an increased attentiveness to equity framing as an essential tool ensuring that equity issues can be understood as a critical part of, and not separate from, science communication. To facilitate this shift, we develop a novel concept of equity framing, based on EJ practices.

Equity framing, meaning framing that centers equity, is concerned with the quality of fairness and inclusion that people receive (Rumley, 2014) and rejects a homogeneous approach to the distribution of justice (Bryner, 2002). By acknowledging preexisting inequalities among social groups, equity framing emphasizes that scientific knowledge is not divorced from the cultural, social and political histories in which it is embedded. In this way, equity framing provides an essential point of access for disadvantaged communities to engage with science communication, and also an important opportunity for researchers and science writers to increase their accountability to disadvantaged communities. When we say science communicators we mean all of these different people: writers, journalists, and teachers, science instructors, and scientists themselves.

Scientific knowledge is not developed through individual facts, but through the achievement of consensus about what counts as facts (Penrose and Katz, 2010). Research suggests that such consensus is built and communicated through discursive framing-with science communicators highlighting particular aspects of a scientific question or findings that are salient to particular audiences (Taylor, 2000; Druckman and Lupia, 2017). Discursive framing refers to the interpretive storylines that set a specific train of thought in motion, by communicating why an issue might be a problem, who or what might be responsible for it, and what should be done about it (Nisbet, 2009). Frames in communication affect audience opinion by not only informing them about an issue, but also creating the potential to reorient their thinking (Lakoff, 2004; Chong and Druckman, 2007).

The importance of framing in science communication may be challenged by advocates for positivist or "objective" science, which builds off the assumption that science can ultimately achieve a single, knowable truth. Debates over the objectivity of science are beyond the scope of this article. However, we discuss science communication from the standpoint that there is no such thing as unframed information. In doing so, we draw attention to the way in which science communication is typically framed, and consider structural elements around who is controlling the dominant communication framing. We also consider the potential for socially engaged science communicators to adopt alternative framings that center equity concerns, and practical tools for doing so.

Science has always been shaped by the values of the dominant culture in which scientists participate and live (Taylor, 2000; Penrose and Katz, 2010). So too has the mainstream framing of science been shaped by the dominant, homogenous voices-scientists and journalists who are predominantly white, educated, and male (Puritty et al., 2017; Grieco, 2018). In contrast, framing that has emerged from the environmental justice movement comes directly from communities of color and other marginalized groups, and thereby reflects their lived experiences. Because environmental justice is the first sector of the environmental movement to frame human-nature relations through the lens of race, class and gender (Taylor, 2016), the EJ movement encourages increased awareness of historical and current inequities in society. Given their direct experiences with discrimination based on social position, e.g., race and class, frontline environmental justice leaders have consistently focused on social equity concerns around environmental issues. As a result, equity framing rooted in EJ traditions involves recognizing how racial minorities and other marginalized groups bear the brunt of the discriminatory environmental policies and practices.

Viewing science communication through an equity lens asks communicators to better understand the ways in which their framing is connected to particular historical practices that have targeted and harmed marginalized communities, and continue to do so, in part through current scientific discourse. To achieve a more inclusive science, science communicators need to understand this broader sociopolitical context, which has been well-documented by environmental justice scholars. Equity framing can help science communicators engage with difficult histories of racialized violence and abuse, and benefit from environmental justice concepts that have "transformed the way mainstream environmentalists think about the environment and also the way many people of color think about it" (Taylor, 2000, p. 17). This is because environmental justice framing requires us to consider the embodied experiences of frontline communities living the realities of racial discrimination and environmental harms-making interconnected social and environmental inequities visible in a new way.

In the following sections, we unpack an equity framing approach that is rooted in EJ scholarship, which can be adopted by science communicators. We center EJ voices and ideas, and apply them in ways that will be useful for science communicators seeking to build a more inclusive approach. We begin by discussing what is at stake if science communicators do not pursue equity framing. We then highlight specific equity framing strategies that emerge from foundational EJ scholarship. Because we do not assume that science communicators have been previously exposed to equity framing, we illustrate our process of teaching equity framing practices through an introductory college course on environmental justice, where we engaged with our students as current and future science communicators.

\section{THE NEED FOR EQUITY FRAMING: HISTORICAL CONTEXT}

To document the need for equity framing, we look to the historical record. The environmental justice literature makes visible the ways that marginalized populations, often made up of people of color or economically marginalized communities, have been treated as inferior and less valuable to society than others. According to Pellow (2016, p. 4), a critical environmental justice (CEJ) intervention shows the ways these communities are marked for erasure and early death, and counters this violence 
with the contention that "threatened bodies, populations and spaces" must be attended to, and that addressing this problem is in fact "indispensible to building" environmentally just futures for all.

Science communication strategies that forward an environmental justice intervention are sorely needed. We see what is at stake, for example, when we examine the impacts of Paul Ehrlich's best-seller The Population Bomb. Ehrlich's text makes the scientific argument that population growth was the cause of the "dying planet" and urges immediate action to save human civilization (Ehrlich, 1968). While we do not take issue with the science behind his study-increasing populations do result in more resources used-his framing of the population "problem" as an issue of human numbers, has had significant negative repercussions (Mann, 2018). Based on the problem framing of "numbers" of people and imminent world collapse, Ehrlich's text emphasizes the need for population control measures that included sterilization, a policy approach that has been applied predominantly to non-white populations in the developing world.

Ehrlich's framing has been and continues to be taken up by others, including mainstream environmental organizations like the Sierra Club (Barringer, 2004), to incite a wave of population alarm, with the blame for global ecological disaster often being placed on the reproductive capacities of the world's poor (Gosine, 2010). In the years immediately following Ehrlich's book, people of color were made the target of unethical, statesponsored population reduction programs and policies that subjected them to experimental procedures and involuntary sterilization programs. This included Native American women across the US and Chicano women in Los Angeles being forcibly sterilized throughout the late 1960s and 70s (Lawrence, 2000; Taylor, 2000). Growing population alarm also contributed to millions of state-sponsored forced sterilizations in India, and large numbers of coerced abortions in China (including selective abortions based on gender) following the adoption of China's “one-child" policy (Mann, 2018).

Environmental journalist David Roberts takes these associations into account when he notes that he never discusses "overpopulation" in his writing. "When political movements or leaders adopt population control as a central concern... let's just say it never goes well. In practice, where you find concern over "population," you very often find racism, xenophobia, or eugenics lurking in the wings. It's almost always, ahem, particular populations that need reducing" (Roberts, 2018). Instead, he argues that when reporting on overpopulation, science communicators might focus on framing that centers family planning research, or on education initiatives for girls, which research suggests are two of the most powerful mitigators that encourage a decrease in human populations and reduce carbon emissions. This example illustrates how science communicators can become self-aware and active agents, attending to the impact of their framing on marginalized communities and their well-being in relation to dominant society. This, we suggest, is one element of equity framing.

\section{EJ SCHOLARSHIP: STRATEGIES FOR MORE INCLUSIVE SCIENCE COMMUNICATION}

Equity framing that is based on environmental justice practices seeks to make discrimination and disproportionately harmful impacts on communities of color and other marginalized groups more visible, and also lifts up community agency and leadership that is occurring in response to such impacts. Centering community leadership is particularly important for disrupting narratives that consistently portray marginalized communities as the victims, lacking the authority and knowledge to develop their own solutions. When making choices about framing, science communicators can also be informed by the leadership of marginalized communities. This intervention can bring about multiple benefits, which include helping communicators avoid racially targeted applications of scientific findings. In this way, environmental justice helps us to challenge dominant framings of the world, and to disrupt harmful scientific narratives that perpetuate racial discrimination.

In the following section, we introduce practical interventions from foundational environmental justice scholarship that science communicators can adopt for building a more inclusive framework that brings a wider spectrum of society into our efforts to understand and address significant environmental challenges. These EJ strategies ask science communicators to (1) become aware of their own positionality and partial perspectives, (2) name sources of inequity that arise from uneven power relations, and (3) find intersections with initiatives that are rooted in the experiences of disadvantaged communities.

First, environmental justice scholars emphasize centering the voices of persons of color in environmental problem solving, along with representatives of other marginalized communitiesa goal which aligns with building more inclusive science communication strategies. Environmental justice scholars explain the need for direct representation by people of color and other disadvantaged groups in communications and decisionmaking through the concept of positionality, which describes how an individual's perspective is shaped by their social position, including class, gender and sexuality, racial identity, and other determinants of social privilege. As an important point of clarification, becoming more aware of one's positionality is not about developing a more pluralistic, multicultural perspective. Rather, it is related to a more difficult task of acknowledging and deconstructing the dominant narratives and personal privileges embodied in our race, class, gender, etc. that shape the ways in which we understand the world.

Discussing positionality in the environmental justice context, Pulido and Peña (1998) consider how people experience environmental problems differently based on their social position. In their analysis of United Farmworkers Organizing Committee (UFWOC) pesticide campaigns from the 1960s in California, for example, Pulido and Peña (1998, p. 38) have documented how farmworker positions differed from mainstream environmentalist groups. Mainstream groups were primarily working for wildlife and consumer protection from 
pesticide residues-issues that were largely removed from social justice concerns. In contrast, farmworkers were concerned about direct human contact with pesticides sprayed in agricultural fields and the resulting health impacts, including reproductive harms. In taking a more radical framing to pesticide issues than mainstream environmentalists, framing that included making the occupational hazards of pesticide use visible, farmworkers were "informed by their working class and subordinated position within a racialized division of labor" (Pulido and Peña, 1998, p. 38).

Importantly, occupational hazards of pesticide use were not included in policy solutions put forward by mainstream environmental groups. It was only widespread consumer boycotts that made their concerns visible to agricultural producers and the public, which finally enabled United Farmworkers labor organizers to gain a voice in decisionmaking. Pulido and Peña (1998) environmental justice analysis underscores the role of positionality in environmental communication, as well as policy formation. The EJ perspective makes visible the vital role that the UFWOC and farmworkers themselves played in creating policy change to address key social justice issues related to pesticide use, and the inability of mainstream actors to fully represent farmworkers experiences and concerns. This was a difficult challenge for UFWOC, which can be understood as follows:

\footnotetext{
"mainstream and subaltern actors hold different positions within the socioeconomic structure that, in turn, frame their struggles differently.... Mainstream activists are involved in negotiating policy. They may stand in solidarity with the affected community, but for subaltern actors it is their land and their bodies that are at risk" (Pulido and Peña, 1998, p. 34).
}

Second, environmental justice scholarship demonstrates how shifting away from a dominant worldview requires seeing and naming sources of inequity in our society, a task that may not come easily for people in all social positions. Through the work of the UFWOC, the broader public began to see how social justice issues were intertwined with mainstream environmental concerns over pesticide use-a shift that occurred when farmworkers demonstrated the embodied, racialized, and uneven distribution of environmental harms resulting from pesticide exposures in the fields. As Pulido and Peña (1998, p. 38) point out, those in more privileged positions may be "incapable of oppositional politics that would allow them to make the connections between agribusiness, the state, environmental degradation, and highly-exploited workers." This is, in part, due to the positionality of mainstream organizations and their leaders, whose social and economic capital (e.g., funding sources, board members, individual social positions) may be more closely tied to dominant structures enabling farmworker exploitation.

As EJ scholars show, it is precisely such attention to the politics, ethics, and structural inequities surrounding our science that will enable a more inclusive understanding of environmental problems. And by expanding our worldview, we can better evaluate multiple policy interventions that consider social equity issues alongside environmental protections. In the pesticides case, for example, the different lived experiences of mainstream environmental organizations and farmworker union organizers contributed to divergent policy goals that separated these two groups. For mainstream environmentalists, the decisions to ban the pesticide DDT was a major win, given constituent concerns around devastating impacts to birds and wildlife from this long lasting pesticide, as well as health concerns regarding persistent pesticide residues in consumer products. After the DDT ban, however, United Farmworkers continued fighting against specific forms of organophosphates, used as a DDT replacement. These organophosphates were acutely toxic, and therefore, more dangerous for workers who were being exposed to these poisons immediately following pesticide application, primarily through contact with foliage. In summary, EJ practices require us to be critically aware of our positionality: what it allows us to see and what it prevents us from seeing, and how this affects our understanding of environmental policy impacts on marginalized communities.

Third, environmental justice scholars emphasize moving beyond dominant environmental narratives by locating strategic intersections with social justice movements, thereby bringing a greater political consciousness to environmental issues. Through her historical analysis of environmental movements, EJ scholar Dorceta Taylor illustrates what it means to use an environmental justice frame to restructure dominant narratives. Taylor (2000) discusses the importance of understanding that EJ movements did not create new discourses or identities from scratch. Instead, the movement adopted highly salient aspects of successful social movements led by communities of color, especially the Civil Rights movement. Early EJ leaders in the 1970s and early 1980s specifically drew from (a) preexisting frames on racism and civil rights, and (b) the identities of labor activists, students, community organizers, academics, and policymakers engaging in current social justice movements.

By engaging with these movements led primarily by communities of color, EJ practices pushed far beyond the typical understanding of the environmental movement and its origin points, which have historically emphasized the perspectives of middle-class white men (e.g., John Muir, Gifford Pinchot) and a romantic view of untouched wilderness. As Taylor (2000, p. 524) explains, the romantic wilderness narrative "does not account for the way in which race, class, gender, labor market experiences, and politics influence environmental activism. It leaves the reader to assume that everyone had similar environmental experiences and responses to environmental occurrences." By using an environmental justice frame, however, Taylor (2000) debunks the dominant narrative and expands what it means to be an "environmentalist," thereby including marginalized communities that have experienced various forms of environmental discrimination:

\footnotetext{
"environmental justice activists do not draw on Romantic/Transcendental images to motivate their supporters. Instead, they evoke images of racism, appropriation of land, and the destruction of communities and cultures. The environmental justice images have their roots in the social justice struggles emanating from the period of conquest and slavery; more
} 
recently, the images draw on potent symbols of the civil rights movement and the struggles of other people of color in the 1960s and 1970s" (Taylor, 2000, p. 514).

In order to deconstruct the environmental movement's dominant narratives, Taylor's research and writing brings to light "the 19th-century experience of people of color (forced relocations, living on reservations, appropriation of land, slavery, and sharecropping, among other things)" (Taylor, 2000, p. 514). Despite the historic whiteness of the environmental movement and its many silences on issues of racial discrimination, the possibility for "equity framing" becomes possible by exploring the intersections between mainstream society and social justice movements that are actively responding to social inequities. It is through such intersections that both mainstream and EJ groups may open up more inclusive science communication and policy spaces that begin to address the needs of less privileged communities in a meaningful way.

To this point, the EJ interventions above intersect with arguments made by feminist scholars, who argue that community standpoints provide a more critical worldview, which encourages the visibility of communities whose concerns are too often erased (Haraway, 1988; Harding, 2004, 2008; Sangtin Writers Collective Nagar, 2006). By becoming more aware of the standpoints of marginalized communities and their lived experiences, as well as developing a critical awareness of our own positionality (e.g., our own race class and gender), we begin to see where our blinders are and to better understand our own "partial perspective." Thus, we hope to "become more answerable for what we learn how to see" (Haraway, 1988, p. 583). Following Haraway’s work on situated knowledge (1998), we refer to this intervention as "situating the science." It is by situating ourselves as science communicators that we may better recognize that all knowledge comes from a speaking position that is affected by social location-the privileges or lack thereof, which arise, for example, from our race, class, or gender identification.

While we draw on foundational EJ texts in this section, we also see these interventions being discussed in current environmental justice research. This evolving field includes EJ scholarship exploring emerging social movements, e.g., climate justice, food justice, energy justice, Indigenous sovereignty movements, etc. (Mohai et al., 2009; Agyeman et al., 2016). It involves critical EJ analyses of globalization and supply chains (Pellow, 2007), as well as EJ solutions calling for "just transitions" to a green economy that address the needs of marginalized communities (Agyeman, 2013). And it also encompasses EJ insights regarding unequal access to environmental privileges, e.g., parks, green space, community services, etc. that have been shaped by longstanding racial and economic segregation (Pulido, 2000; Park and Pellow, 2011; Snyder et al., 2014; Corbin, 2018).

\section{TEACHING INCLUSIVE SCIENCE COMMUNICATION: A CASE STUDY}

In this section we draw on our experiences teaching the first Introduction to Environmental Justice survey course at Stanford

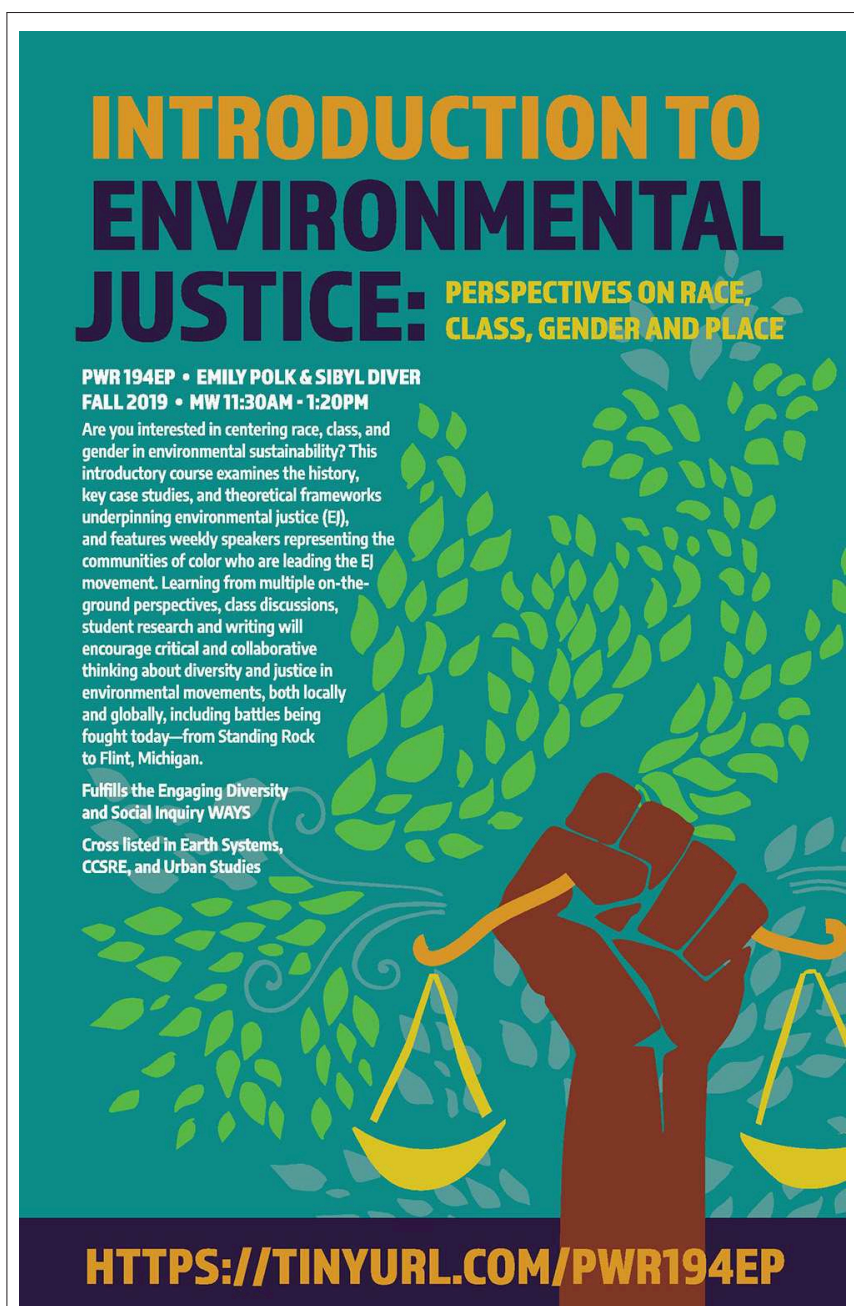

FIGURE 1 | Intro to Environmental Justice course poster, designed by Stephanie Muscat, Sibyl Diver, and Emily Polk. Used with permission.

University to illustrate one example of how equity framing rooted in environmental justice practices can be taught and applied to science communicators (Figure 1). The main question driving this article-how can we build more inclusive science communication - also provided the grounding for our pedagogy. Our class engaged deeply in questions of inclusivity: How do I write in a way that makes the problems disadvantaged communities face and their solutions more visible? How do I do this in a way that does not render the knowledge and leadership of disadvantaged communities invisible? How do I ground my scientific research in larger social and political contexts that make our knowledge more complete? How has my own positionality affected my research questions, research design, and communication choices? And how do I effectively communicate with my intended audience(s) about equity issues, as an important part of the story?

To demonstrate our approach, we highlight four elements of our pedagogy drawing from EJ practices and equity framing: (1) Situating ourselves as a model for our students; 
(2)Intentionally setting an inclusive tone and situating ourselves in EJ conversations; (3) Developing a diverse curriculum that centers committees of color, and other marginalized groups; (4) Emphasizing teaching from frontline EJ communities who use narrative storytelling and other tools for reimagining a more equitable world as a reclamation of community agency; and (5) Asking students to practice equity framing rooted in EJ practices in their own science communication, which we facilitated though an independent student research assignment. These classroom experiences trained our students to see equity issues through an EJ lens, and also to imagine how they could best situate themselves, given their own social positions, in their own communication. We see these two skills as core components of "equity framing."

While we recognize Stanford as an elite institution with greater capacity to support direct community engagement in the classroom, we suggest that our approach can be adopted across a range of higher education institutions. It is important to note that our class community included 20 students from diverse race, class and gender backgrounds, many of whom were from or connected to frontline communities experiencing disproportionate environmental harms. Financial support for this course originated from a variety of cross-campus interdisciplinary collaborations-departments and programs that had long heard the student demand for more courses focused on environmental justice and wanted to be involved. When bringing frontline community leaders to our classroom, we opened up these sessions to the entire campus as an EJ speaker series, in order to afford greater access to their knowledge and experiences, and to build greater legitimacy and support for our work. While meeting community leaders in person was highly impactful, we also supplemented curriculum materials with videos and direct testimonies from frontline communities, as an additional low-cost strategy that can be employed by a wide range of educational institutions.

The foundation of our course was the community we created within our classroom. To model best practices for equity framing, we began by situating ourselves as course instructors. Polk is an environmental communication scholar at Stanford who studies the mobilization of community led social movements that arise as a response to climate change. Her interest in environmental justice began as a human rights journalist working for years with marginalized communities in Nepal, on the Thai/Burma border, and in a Liberian refugee camp in Ghana. She currently lives in the East Bay region near San Francisco where her community is directly impacted by a myriad of environmental justice issues. Diver is an environmental social scientist at Stanford. She is originally from a small coastal town in Delaware, with Irish and English heritage. She does community-engaged scholarship on Indigenous water governance in the Pacific Northwest. This includes a long-term research partnership with the Karuk Tribe, which is working to protect and restore cultural resources on aboriginal territory that is currently recognized as National Forest. She began working on these issues as a Russian translator, facilitating international exchanges for Indigenous community leaders on land rights and Indigenous resource management. Together the two instructors have more than
40 years of combined experience working with communitybased organizations working on environmental and human rights issues.

To set an inclusive tone that enabled critical, yet mutually supportive discussions, we invited Dr. Roxy Manning, a licensed clinical psychologist and (Nonviolent Communication) NVC Certified Trainer as our first speaker. Dr. Manning spoke to our class about her personal experiences as an Afro-Caribbean immigrant who had recently lost her young son, along with her professional experience leading trainings around the world. Continually returning to the importance of cultivating empathy for ourselves and for others, her workshop gave our class language to communicate the emotional challenges that arise from immersing oneself in environmental justice work, and tools for authentically engaging with our own social positions.

Dr. Manning's training underscored the need for personal reflection on our situated position in society, especially when attempting a more inclusive approach to science communication. As Dr. Roxy explained, "When working in communities, we need to be aware of our own privilege." If not, she added that you are in danger of (1) taking control, and (2) preferentially holding your own perspective as legitimate. As Dr. Manning pointed out, "we don't know what we don't know." Manning described her own reflexive process, recognizing the limitations of her knowledge in communications with others. When entering a new situation, she reminds herself, "I need to get quiet, and I need to get curious." To support Mannings teachings about how we can respectfully discuss complex issues of race, class, and privilege, we combined Dr. Manning's teaching with a critical discussion on situated knowledge.

This approach emphasized entering conversations with humility. Honing our ability to listen to individuals from a different social position than ourselves can have profound implications for learning and communicating. At the same time, Dr. Manning clarified how cultivating humility does not mean abdicating the privileges that may arise from one's social positioning. Rather, she encouraged individuals to become selfaware of their privilege and leverage it appropriately. As Manning told us, "we need allies." In a classroom at Stanford, this line of conversation inevitably directs us to the question, what do we do with our own personal privilege, when entering into social justice spaces? We also encouraged students to appreciate their ability to know based on their individual social positions and embodied experiences."

The third element of our pedagogy involved developing a diverse curriculum that offered students a foundation in the history of environmental justice, through historical accounts coming directly from the EJ organizers, theorists, and scholars of color. We paid keen attention to centering voices from communities of color and other marginalized groups. By challenging dominant mainstream framing in environmental science that does not include scholarship by persons of color, this approach provided a more complete knowledge of the uneven power relations and discriminatory practices driving environmental justice problems, and an entry point for students from more privileged backgrounds into challenging social justice issues. It also enabled students of color and 
other marginalized students, some of whom were from the communities we were reading about, to see their own selves reflected back to them-an important consideration for science communicators who seek to build trust with a broader audience.

A fourth component was emphasizing the teachings of frontline communities, which we accomplished through interactive workshops with frontline environmental justice leaders. We invited EJ leaders to guest teach on a range of issues, including climate justice, food justice, queer ecologies, Afrofuturism, Indigenous knowledge, toxic waste exposures, among other topics. By having frontline EJ leaders as our teachers we disrupted traditional notions of expert knowledge production in environmental science. Students learned best practices for building more inclusive science communication through listening to these community voices, their unique stories, and their particular strategies, especially community-led resilience in the face environmental disparities. For example, Karuk tribal member and traditional dip net fisherman Ron Reed from the Karuk Tribe explained dam construction on the livelihoods, health, and culture of tribal members. Haleh Zandi of Planting Justice described her work supporting recently incarcerated individuals with work and healing as part of an intentional and diverse urban agriculture community. And Chryl Corbin, a scholar activist working with Oakland City Parks, spoke about how she uses Afrofuturism-inspired tactics to encourage city employees to reimagine themselves as green JEDI (justice, equity, diversity, and inclusion) warriors, working together with African American community members.

It was through the storytelling of EJ leaders that students gained tools for "seeing" EJ problems for the first time, as well as imagining innovative solutions through an EJ lens. For example, following one lecture where we viewed architectural mock-ups of Oakland City "green" development, one student shared her experience realizing that she failed to notice that there were no black people included in the pictures of the professional "revision" of Oakland waterfront areas that were historically the center of black culture. But instead of leaving students with a hopeless problem, speakers encouraged us to draw on art, science, fiction, and other sources of inspiration to reenvision and communicate the possibilities for a more equitable society.

Learning how to communicate in ways that sustain and support these solutions included finding pathways for meaningful allyship between marginalized communities and individuals coming from more privileged social positions. Paloma Hernandez, a Stanford graduate and EJ campaigner working in South LA, where she grew up in the Latinx community, shared some "working guidelines" for EJ allies that emphasized the importance of listening to communities. These including the following:

- "When we see a "disadvantaged community," we too often see only what it doesn't have and not what it does. Community power exists wherever you go, sometimes where you least expect it.

- Don't presume to have the answers. You might have research concluding one thing, which is great. But if a community org believes another thing, you need to really put on your listening ears to understand why. Reality is nuanced. Our lives are complex.

- Sometimes there will be spaces you will want to enter, and you might have the very best intentions, and you will still not be wanted. You might have to just let it go."

As a final teaching strategy, we asked our students to practice equity framing through developing their own research project that offered a unique contribution to our environmental justice conversations and environmental communication. This was a carefully scaffolded assignment, which provided students with sense of agency in the writing and research process. It also enabled students to support one another and build community together through ongoing peer review. The research assignment gave students the opportunity to write about any issue that they wanted, with diverse topics ranging from policy analyses of lowincome weatherization programs to case studies of food justice organizations to intersections between religion and responses to climate change. Their geographic locations were also diverse, covering fracking in Pennsylvania, water justice in Michigan, housing rights in North Carolina, and public health in Hawaii, to name a few. We note the diversity in topic and geography to suggest the possibilities for communicating environmental research using an equity frame.

To encourage a more inclusive approach to science communication, we required our students to use a range of sources that included community voices, and to consider who counted as an authority on their topic and why. This challenged traditional academic notions of expertise and creating space for our students to mobilize different kinds of authority, particularly the voices of impacted communities. We also asked students to identify their intended audience, and which genre of media would be most effective in reaching that audience. By intentionally analyzing the audience and genre, students needed to find the appropriate language to effectively engage with their intended audience, engage with the sociopolitical context of their research, and consider real world applications for scientific findings. These rhetorical considerations aid in what Lupia (2013) calls "source credibility." Recent research shows it is the communicators who emphasize common interests with their audience and relevant expertise who are most effective at establishing themselves as a credible, or trustworthy source. Building trust is fundamental to inclusive science communication and cannot be developed without an attention to the needs of an audience and the researcher's own positionality.

We also asked students to negotiate their positionality through the research process. Note that a positionality statement was not necessarily part of the final written product, and we do not support navel gazing in research or writing. However, we wanted students to practice situating their own identity (race, gender, class) as part of their thinking, research, and communication practices. We also wanted them to understand how their social position relative to an EJ issue could help them build credibility in their communication. We asked each student to work in small groups and discuss the following questions: What is your own positionality as a researcher? How do your various 
identities intersect with the questions you have asked? What experiences inspired you to ask the questions you do? How might they influence the way you interpret and select your sources? What affordances are you offered by your positionality? What particular vantage point do you have that is unique from others?

By asking students to consider the ways their own experiences and identities intersect with their research questions, we intentionally prepared them to conduct a more nuanced and contextual analysis, working toward a more just and inclusive communication process. Their learning through this process is illustrated by some of our students' reflections about the class, included here.

Science is often depicted as apolitical and empirical, beyond the influence of culture and politics... Scientific knowledge should be situated knowledge. I learned about how science can often take "a view from nowhere" which obscures the positionality of the researcher. This discussions made me think critically about how the narratives presented in some of my biology classes often conveyed knowledge in an ahistorical and apolitical way that hides the connections between the history of biology and the history of colonial and racial injustices.

Week after week the speakers shocked, surprised, challenged, imagined with us. Young black and brown folks came into our little [Wallenberg] spaces and showed us how to rewrite narratives. They came with a range of emotions and tactics from militance and liberation to curiosity and queering (a verb is a doing word). We talked about the evolution of EJ and the intersectionality in movements and stories. Are we fighting or are we empathizing? Both. Both and. Both and also therefore.

Not only have we thought and learned and expanded our frame of what it means to be an environmentalist, learning (in my case) about nuance and struggles that don't directly affect us or have been erased, we have also learned, nay been pushed, to contemplate how to generate, and how our research projects and voices might add to the movement or literature on EJ to further things moving forward. You've opened my eyes to problems I'd heard about but didn't really comprehend, and histories I'd never knew. You make me think about organizing in a totally new way. Honestly, if I'm aware enough I'll probably spend the rest of my life digesting this class.

In sharing these highlights, we do not wish to suggest that the learning process was easy. Building the skills for more inclusive science communication through EJ practices required intentionality, an investment in time and energy, and willingness to learn from one another. In this way, our classroom environment was not unlike the process of scientific discovery in itself-an iterative process built on curiosity, collaboration and commiseration; learning from mistakes; listening to each other, and supporting one another in the development of a project that could contribute something larger than our individual selves.

\section{THE TRANSFORMATIVE POTENTIAL OF EQUITY FRAMING}

In conclusion, we argue that equity framing can be transformative for science communication because it leads to a greater ability to communicate in a more inclusive manner.
Equity framing makes visible the inextricable connections between science and society in ways that serve a broader segment of society, including groups that are disadvantaged by their social position (e.g., race, class, gender, etc.) As a case in point, we can look to the impact of environmental justice on the broader environmental movement,

\footnotetext{
"The environmental justice discourse has also transformed the way mainstream environmentalists think about the environment and also the way many people of color think about and relate to the environment. Because of environmental justice, it is no longer considered appropriate for mainstream environmentalists to define and analyze environmental issues without considering the social justice implications of the problem" (Taylor, 2000, p. 523).
}

Thus, we suggest that incorporating EJ practices and equity framing into science communication does more than support inclusive communication for marginalized communities. Rather, it benefits all people, in the following ways. First, by including the concerns and insights of marginalized communities as part of science communication, we can increase the social relevance of scientific findings and build greater trust in knowledge production occurring within the academy, specialized laboratories, or other isolated spaces of inquiry. Second, by communicating scientific problems in a way that connects with more diverse and marginalized communities, we invite these communities to participate in scientific knowledge production, and thereby add important experiences and perspectives to a career field that has historically been dominated by white males. This intervention breaks down hierarchies to encourage a more complete understanding of the world. Third, by addressing equity concerns in our science communication, and in our science, we may better contribute to building a healthier society for all.

This article also leads to a number of important questions about next steps for building more inclusive science communication. How can science communicators play a part in preventing the silences and erasures of the knowledge and experiences of marginalized communities on the frontlines of our most significant environmental crises? EJ teaches us that it is the representatives of disadvantaged communities who need to become science communicators, in order to more effectively speak for themselves and their lived experiences. How can we each support this process as scholars, as scientists, as journalists, and as change makers?

Building on our experiences teaching environmental justice to future science communicators, we suggest that science communicators can learn to speak from an allied position, perhaps by intentionally reflecting on their own positionality and finding authentic points of intersection with the needs and priorities of disadvantaged communities. But in doing so, how do science communicators better involve leadership from disadvantaged communities in their writing and research processes, without introducing additional burdens?

We acknowledge that these are big and timely questions given the magnitude of social and environmental crises 
facing our communities. We also acknowledge that science communicators-journalists and teachers and scientistsbear a tremendous responsibility with framing scientific knowledge, including environmental science, in ways that are critically attuned to equity. We turn our attention to equity framing as one solution because such a framing addresses the visceral experiences of frontline communities often left out of dominant narratives; and helps us to consider our own positionality in the research and communication process, perhaps enabling a form of science communication that contributes to more impactful collective action. As demonstrated through our classroom teaching, this is a challenging task, which requires creating greater intellectual and emotional space for science communicators to engage with social and environmental justice concerns. Through our application of equity framing techniques, we seek to achieve more inclusive science communication, as well as a more just and sustainable world.

\section{REFERENCES}

Agyeman, J. (2013). Introducing Just Sustainabilities: Policy, Planning, and Practice. London: Zed Books Ltd.

Agyeman, J., Schlosberg, D., Craven, L., and Matthews, C. (2016). Trends and directions in environmental justice: from inequity to everyday life, community, and just sustainabilities. Annu. Rev. Environ. Resour. 41, 330-336. doi: 10.1146/annurev-environ-110615-090052

Barringer, F. (2004). Bitter division for sierra club on immigration. New York Times. Retrieved from: https://www.nytimes.com/2004/03/16/us/bitterdivision-for-sierra-club-on-immigration.html?mcubz $=0 \& \_r=0$ (accessed July 31, 2019).

Bryner, G. (2002). "Assessing claims of environmental justice," in Justice and Natural Resources: Concepts, Strategies, and Applications, eds K. M. Mutz, G. C. Bryner, and D. S. Kenney (Washington, DC: Island Press).

Bullard, R. D. (1993). Race and environmental justice in the United States. Yale J. Int. Law 18, 319-335.

Bullard, R. D. (Ed.). (1996). Unequal Protection: Environmental Justice and Communities of Color, 2nd edn. San Francisco, CA: Sierra Club Books.

Bullard, R. D. (2000). Dumping in Dixie: Race, Class and Environmental Quality, $3 r d$ edn. Boulder: Westview Press.

Chong, D., and Druckman, J. N. (2007). Framing theory. Annu. Rev. Polit. Sci. 10, 103-126. doi: 10.1146/annurev.polisci.10.072805.103054

Corbin, C. N. E. (2018). "Wakanda! take the wheel! visions of a black green city." Special issue, race and spatial imaginary: planning otherwise. Plann. Theor. Pract. 19:273-275. doi: 10.1080/14649357.2018.1456816

Druckman, J., and Lupia, A. (2017). "Using frames to make scientific communication more effective," in The Oxford Handbook of the Science of Science Communication, eds K. H. Jamieson, D. Kahan, and D. A. Scheufele (New York, NY: Scheufele Oxford University Press). doi: 10.1093/oxfordhb/9780190497620.013.38

Ehrlich, P. (1968). The Population Bomb. Rivercity, MA: Rivercity Press.

Gosine, A. (2010). "Nonwhite reproduction and same-sex eroticism: queer acts against nature," in Queer Ecologies, eds C. Mortimer-Sandilands and B. Erickson (Bloomington: Indiana University Press).

Grieco, E. (2018). Newsroom Employees Are Less Diverse Than US Workers Overall. Pew Research Center. Retrieved from: https://www.pewresearch. org/fact-tank/2018/11/02/newsroom-employees-are-less- diverse-than-u-sworkers-overall/ (accessed July 29, 2019).

Haraway, D. (1988). Situated knowledges: the science question in feminism and the privilege of partial perspective. Fem. Stud. 14, 575-599. doi: 10.2307/3178066

Harding, S. (2004). "Introduction: standpoint theory as a site of political, philosophic, and scientific debate," in The Feminist Standpoint Theory Reader:

\section{DATA AVAILABILITY STATEMENT}

All datasets generated for this study are included in the article/supplementary material.

\section{AUTHOR CONTRIBUTIONS}

The ideas in this manuscript emerged during many conversations across several years between EP and SD as they developed Stanford's first comprehensive Introduction to Environmental Justice course.

\section{FUNDING}

Funding for the Introduction to Environmental Justice course was provided by the Program in Writing and Rhetoric and the School of Earth, Energy, and Environmental Sciences at Stanford University.

Intellectual and Political Controversies, ed S. Harding (New York, NY: Routledge), 1-15.

Harding, S. (2008). Sciences From Below: Feminisms, Postcolonialities, and Modernities. Durham: Duke University Press. doi: 10.1215/9780822381181

Lakoff, G. (2004). Don't Think Of An Elephant! How Democrats And Progressives Can Win Know Your Values And Frame The Debate: The Essential Guide For Progressives. Chelsea Green Pub Co.

Lawrence, J. (2000). The indian health service and the sterilization of native American women. Am. Indian Q. 24, 400-419. doi: 10.1353/aiq.2000.0008

Lupia, A. (2013). Communicating science in politicized environments. Proc. Natl. Acad. Sci. U.S.A. 110, 14048-14054 doi: 10.1073/pnas.1212726110

Mann, C. C. (2018). The Book That Incited a Worldwide Fear of Overpopulation. Smithsonian, Magazine. Retrieved from: https://www.smithsonianmag. com/innovation/book-incited-worldwide-fear-overpopulation-180967499/\# KWAz6P1H25YG6yIm.99 (accessed February 12, 2020).

Mohai, P., Pellow, D., and Timmons, R. J. (2009). Environmental justice. Annu. Rev. Environ. Res. 34, 405-430. doi: 10.1146/annurev-environ-082508094348

Nisbet, M. C. (2009). Communicating climate change: why frames matter for public engagement. Environment 51, 12-23. doi: 10.3200/ENVT.51.2.12-23

Park, L. S. H., and Pellow, D. (2011). The Slums of Aspen: Immigrants Versus the Environment in America's Eden. New York, NY: New York University Press.

Pellow, D. (2016). Toward a critical environmental justice studies: black lives matter as an environmental justice challenge. DuBois Rev. 13, 1-16. doi: 10.1017/S1742058X16000175

Pellow, D. N. (2007). Resisting Global Toxics: Transnational Movements for Environmental Justice. Cambridge, MA: The MIT Press. doi: 10.7551/mitpress/7479.001.0001

Penrose, A. M., and Katz, S. B. (2010). Writing in the Sciences: Exploring Conventions of Scientific Discourse. New York, NY: Pearson Longman.

Pulido, L. (2000). Rethinking environmental racism: white privilege and urban development in southern california. Ann. Assoc. Am. Geogr. 90, 12-40. doi: 10.1111/0004-5608.00182

Pulido, L., and Peña, D. (1998). Environmentalism and positionality: the early pesticide campaign of the United Farm Workers' organizing committee, 196571. Race Gender Class 6, 33-50.

Puritty, C., Strickland, L. R., Alia, E., Blonder, B., Klein, E., Kohl, M. T., et al. (2017). Without inclusion, diversity initiatives may not be enough. Science 357, 1101-1102. doi: 10.1126/science.aai9054

Roberts, D. (2018). I'm an Environmental Journalist but I Never Write About Overpopulation. Here's why. Retrieved from: https://www.vox.com/energyand-environment/2017/9/26/16356524/the-population-question (accessed July 29, 2019) 
Rumley, M. (2014). Equity: A Strong Model for Environmental Justice. The EPA Blog. Retrieved from: https://blog.epa.gov/2014/01/09/equity-a-strong-modelfor-ej/ (accessed July 30, 2019).

Sangtin Writers Collective and Nagar, R. (2006). Playing With Fire: Feminist Thought and Activism Through Seven Lives in India. Minneapolis, MN: University of Minnesota Press.

Snyder, R. E., Jaimes, G., Riley, L. W., Faerstein, E., and Corburn, J. (2014). A Comparison of social and spatial determinants of health between formal and informal settlements in a large metropolitan setting in Brazil. J. Urban Health. 91, 432-445. doi: 10.1007/s11524-013-9848-1

Taylor, D. (1997). American environmentalism: the role of race, class and gender in shaping activism 1820-1995. Race Gender Class 5, 16-62.

Taylor, D. (2016). The Rise of the American Conservation Movement: Power, Privilege, and Environmental Protection. Durham, NC: Duke University Press. doi: $10.1215 / 9780822373971$
Taylor, D. E. (2000). The rise of the environmental justice paradigm: injustice framing and the social construction of environmental discourses. Am. Behav. Sci. 43, 508-580. doi: 10.1177/0002764200043 004003

Conflict of Interest: The authors declare that the research was conducted in the absence of any commercial or financial relationships that could be construed as a potential conflict of interest.

Copyright $(2020$ Polk and Diver. This is an open-access article distributed under the terms of the Creative Commons Attribution License (CC BY). The use, distribution or reproduction in other forums is permitted, provided the original author $(s)$ and the copyright owner(s) are credited and that the original publication in this journal is cited, in accordance with accepted academic practice. No use, distribution or reproduction is permitted which does not comply with these terms. 